Annals of Plant Sciences

ISSN: 2287-688X

OPEN ACCESS

www.annalsofplantsciences.com

Research Article

\title{
Micropropagation of $B$. monnieri using humin media in plant tissue culture
}

Suman Kashyap ${ }^{*}$, Neera Kapoor ${ }^{2}$, Radha D. Kale ${ }^{3}$

${ }^{1}$ Department of Biotechnology and Centre for Scientific Research and Advanced Learning, Mount Carmel College, Bengaluru, India

2School of Sciences, Indira Gandhi National Open University (IGNOU), Maidan Garhi, New Delhi-110068, India.

${ }^{3}$ Centre for Scientific Research and Advanced Learning, Mount Carmel College, Bengaluru, India.

Received: February 28, 2017; Accepted: March 21, 2017

\begin{abstract}
Humus is a complex material formed during the breakdown of organic matter. Earthworm castings contain a high percentage of humus. These humic substances are capable of improving plant nutrition and growth, reminiscent of hormones. Residue obtained after acid-base treatment of vermicompost was used as plant tissue culture media for the micropropagation of Bacopa monnieri. Tukey's Studentized Range (HSD) Test has clearly indicated that development of leaves from nodes was significantly higher in humin alone without any supplements. The $F$ value was 5.5 and $\operatorname{Pr}>\mathrm{F}$ was 0.0087 . The weight of the plantlets (in milligrams) was significantly higher in the humin medium and humin supplemented with vitamins and micronutrients but was least in the humin medium with growth regulators. The difference observed was at the level of $<0$. 0001. The explant development on humin alone has shown the significant percentage survival of in vitro micropropagated plantlets when compared with other treatments. Explants responded maximum to humin only but not so on adding the supplements and the level of significance was at $\operatorname{Pr}>\mathrm{F}$ was $<0.0001$. The maximum growth stimulatory effect was found in aqueous extract of vermicompost which can be made out from the Student's t-test performed to compare the means of weight of plantlets grown on humin and vermicompost extract media with and without chemical supplements respectively. The probability of this result, assuming the null hypothesis is 0.0014 .
\end{abstract}

Key words: Humin media; B. monnieri; economical media; micropropagation; vermicompost extract

\section{Introduction}

Earthworms in nature produce several effective humic substances (Cacco and Agnola, 1984; Nardi et al., 1994; Masciandaro et al., 1997). Humus is a complex material formed during the breakdown of organic matter. One of its components, humic acid, provides many binding sites for plant nutrients, such as calcium, iron, potassium, sulphur and phosphorus. These nutrients are stored in the humic acid molecule in a form readily available to plants. Humic acids contain one of the major fractions of humic substances. They are identified as dark, alkali-soluble, acid-insoluble and highly humified organic matter (Schnitzer, 1991). These humic substances are capable of improving plant nutrition and growth, reminiscent of hormones (Vaughan and Malcolm, 1985; Chen and Aviad, 1990).

Earthworm castings contain a high percentage of humus. Humus helps soil particles to form clusters, which create channels to access air and improve water retention. Humus is intended to prevent precarious plant pathogens, fungi, nematodes and bacteria. The previous reports have shown that the incorporation of humic acids extracted from pig manure vermicompost using the classic alkali/acid fractionation procedure mixed with soilless container medium (Metro-Mix 360) increased the

*Corresponding Author:

Dr. Suman Kashyap,

$281,100 \mathrm{ft}$ ring Road, $7^{\text {th }}$ Block, $4^{\text {th }}$ Phase,

Banashankari $3^{\text {rd }}$ stage, Bengaluru-560085, India.

E-mail: sumkash925@gmail.com growth of tomato plants significantly. Humates extracted from pig manure and food wastes vermicompost mixed with vermiculite increased the growth of cucumber plants significantly (Atiyeh et al., 2002). Humic acids isolated from earthworm compost have increased the root elongation, lateral root emergence, and plasma membrane $\mathrm{H}^{+}$-ATPase activity in maize roots (Canellas et al., 2002). The humic substances at the concentration of $1 \mathrm{mg} / \mathrm{L}$ produced higher number of leaves in explants of Nicotiana plumbaginifolia than those grown in the control. Quantitative differences were also observed in the esterase and peroxidase activity during growth (Muscolo et al., 1993). Earthworms promote the production of plant hormones - auxins, gibberellins and cytokinins from organic waste. Auxins are responsible for cell elongation, cytokinins for promoting cell division and gibberellins for stem elongation. These hormones are dose significant and play a fundamental role in plant metabolism. They can influence plant growth and development as well as crop quality significantly when present at very low concentrations (Atiyeh et al., 2001).

Direct organogenesis of B. monnieri was induced from node and shoot tip as explants collected from the field grown plants. The principal active factors

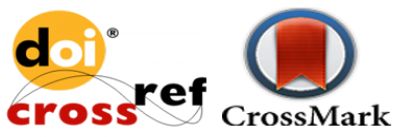


in Bacopa are two steroidal saponins, bacosides A and B ("memory chemicals"), that help repair damaged neurons by enhancing proteins involved in the regeneration of neural-cell synapses (Rastogi et al., 1994). B. monnieri is one among the seven medicinal plants recommended for immediate attention by NMPB and Technology Information Forecasting and Assessment Council (TIFAC) and categorized in the list of highly endangered medicinal plants in India. The annual market demand for brahmi is estimated around 1,000 tonnes during 2007 (National Medicinal Plants Board, 2007) and is likely to be more in the upcoming years due to its multipurpose therapeutic uses.

In vitro regeneration and micropropagation of brahmi was reported by many researchers (Tiwari et al., 1998, 2000, 2001, 2006; Shrivastava and Rajani, 1999; Tejavathi and Shailaja, 1999; Mohapatra and Rath, 2005; Ramesh et al., 2006; Praveen et al., 2009). A two-stage culture procedure has been developed for highly efficient shoot regeneration from leaf and internode explants of $B$. monnieri. Adventitious shoot buds were obtained on the shoot induction medium containing Murashige and Skoog's (MS) basal salt supplemented with $1.5 \mathrm{mg} / \mathrm{L}$ thidiazuron and $0.5 \mathrm{mg} / \mathrm{L}$ naphthalene acetic acid (NAA). (Ceasar et al. 2009).

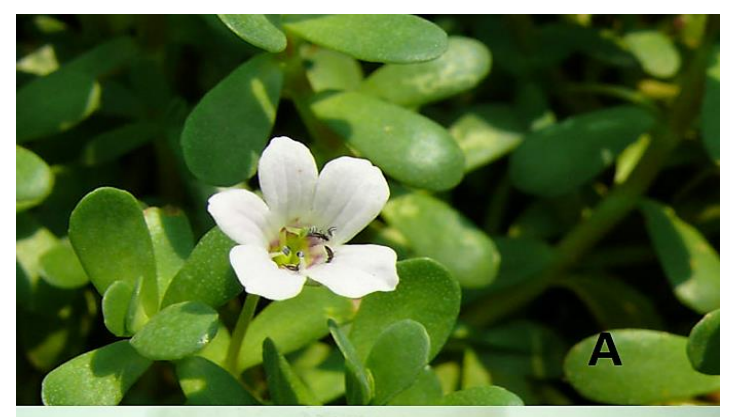

B

Figure: A: B. monnieri;

Figure: A: Micropropagation of B. monnieri on Humin media.

\section{Materials and Methods}

Collection of Medicinal Plant Sample (Explants)

Explants from certified disease-free B. monnieri plants were obtained from Botanical Garden of University of Agricultural Sciences (UAS), Gandhi Krishi Vigyan Kendra, Bangalore. Plants were planted in potted soil at the institution.

\section{Production of Vermicompost}

Vermicompost produced by the activity of epigeic earthworms Eudrilus engeniae on organic waste mix of plant litter, vegetable waste and cow dung slurry at the college campus was used for the present study. Different fractions of vermicompost (1-30 per cent) containing humic and fulvic acids were used to prepare the medium. Vermicompost was sieved for collecting only the castings.

\section{Use of humin as nutrient plant tissue culture} medium

Residue obtained after acid-base treatment of vermicompost was further washed several times with distilled water and sterile distilled water subsequently to remove traces of acid and base. Humin obtained was used to prepare the medium. Known volume of humin media was supplemented with required concentration of micronutrients (1 $\mathrm{ml} / \mathrm{L}$ from the $10 \mathrm{X}$ stock solutions of micronutrients purchased from $\mathrm{Hi}$ media) and supplemented with 9 grams/L of agar and mixed thoroughly. Known volume of humin media was supplemented with required concentration of vitamins (purchased from $\mathrm{Hi}$ media) and supplemented with 9 grams/L of agar and mixed thoroughly.

Humin media were adjusted to $\mathrm{pH}$ 5.8-6.0 using $1 \mathrm{~N}$ $\mathrm{NaOH}$ and $1 \mathrm{~N} \mathrm{HCl}$. All the media samples were autoclaved at $121^{\circ} \mathrm{C}$ for 20 minutes at 15 psi pressure and transferred to the media storage room where they were kept under aseptic conditions till their further use. Sterile explants of B. monnieri were inoculated into the humin media containing 3.0 $\mathrm{mg} / \mathrm{L}$ of BAP and $1 \mathrm{mg} / \mathrm{L}$ of IAA for shoot proliferation.

\section{Explant sterilization}

B. monnieri chosen for in vitro micropropagation were washed under running tap water for 30 minutes in order to wash off the externally adhered soil, dust and other contaminants. The nodal segments were cut into $1.5 \mathrm{~cm}$ to $2.0 \mathrm{~cm}$ length with single node and inter node intact. These nodal and inter nodal cuttings were washed with 5 per cent $(\mathrm{v} / \mathrm{v})$ detergent solution (Teepol) for 10 minutes followed by a rinse with running tap water for several times. In the laminar chamber the nodal segments of $B$. monnieri were further treated with 70 per cent alcohol for one minute followed by 0.1 per cent (w/v) Mercuric chloride treatment for 5 minutes. Aseptically explants were washed with sterile distilled water for three to four times and leaves were removed using sterile blade.

Sterile explants of B. monnieri were inoculated into the media jars. The experiments were carried out in culture rooms under 16 hours cycled cool white fluorescent 1ight of average 2500 lux (cool white fluorescent tube light $40 \mathrm{~W}$ ) and at $25 \pm 2{ }^{\circ} \mathrm{C}$, with a 
photoperiod of 16 hours' day light and 8 hours night breaks.

\section{Experimental Data Analysis}

ANOVA, Student's t-test and Tukey's Studentized Range or Tukey's Honestly Significant Difference (HSD) Test were considered for analyses of significance of various parameters and were carried out to compare the mean number of nodes, leaves, roots and shoots formed in the conventional MS medium and the Humin with respect to B. monnieri. The 'P' values less than 0.05 were considered as indicative of significance. The analysis was performed using SAS statistical software.

Table 1: Tukey's Studentized Range (HSD) Test for development of shoots from nodal explants of $B$. monnieri grown on humin media (vermicompost treated with acid-alkali) with and without chemical supplements

\begin{tabular}{lccccc}
\hline Source & DF & $\begin{array}{l}\text { Anova } \\
\text { SS }\end{array}$ & $\begin{array}{l}\text { Mean } \\
\text { Square }\end{array}$ & $\begin{array}{l}\text { F } \\
\text { Value }\end{array}$ & $\begin{array}{l}\text { Pr } \\
>\text { F }\end{array}$ \\
\hline Types of Media & 3 & 0 & 0 &. \\
& Mean & N & Tukey Grouping \\
Humin only & 1.000 & 5 & A & \\
Humin+IAA+BAP & 1.000 & 5 & A & \\
Humin+Micronutrients & 1.000 & 5 & A & \\
Humin+Vitamins & 1.000 & 5 & A & \\
\hline
\end{tabular}

Note: $\mathrm{IAA}=$ Indole-3-acetic acid; $\mathrm{BAP}=6$-Benzyl amino purine

Table 2: Tukey's Studentized Range (HSD) Test for development of nodes from nodal explants of $B$. monnieri

grown on humin media (vermicompost treated with acid-alkali) with and without chemical supplements

\begin{tabular}{lccccc}
\hline Source & DF & Anova SS & Mean Square & F Value & Pr > F \\
\hline Types of Media & 3 & 3.80 & 1.26 & 5.07 & 0.0118 \\
\hline Mean & N & \multicolumn{3}{c}{ Tukey Grouping } \\
\hline Humin only & 2.6000 & 5 & \multicolumn{2}{c}{$\mathrm{A}$} \\
Humin+Vitamins & 1.8000 & 5 & $\mathrm{~B}$ & $\mathrm{~A}$ \\
Humin+Micronutrients & 1.8000 & 5 & $\mathrm{~B}$ & $\mathrm{~A}$ & \\
Humin+IAA+BAP & 1.4000 & 5 & $\mathrm{~B}$ & \\
\hline
\end{tabular}

Note: $\mathrm{IAA}=$ Indole-3-acetic acid; $\mathrm{BAP}=6$-Benzyl amino purine

Table 3: Tukey's Studentized Range (HSD) Test for development of leaves from nodal explants of $B$. monnieri grown on humin media (vermicompost treated with acid-alkali) with and without chemical supplements

\begin{tabular}{lllllc}
\hline Source & DF & Anova SS & Mean Square & F Value & Pr $>$ F \\
\hline Types of Media & 3 & 18.55 & 6.18 & 5.50 & 0.0087 \\
\hline & Mean & N & Tukey Grouping & \\
\hline Humin only & 5.2000 & 5 & & & $\mathrm{~A}$ \\
Humin+micronutrients & 3.6000 & 5 & & $\mathrm{~B}$ & $\mathrm{~A}$ \\
Humin+vitamins & 3.2000 & 5 & $\mathrm{~B}$ & \\
Humin+IAA+BAP & 2.6000 & 5 & $\mathrm{~B}$ & \\
\hline
\end{tabular}

Note: $\mathrm{IAA}=$ Indole-3-acetic acid; $\mathrm{BAP}=6$-Benzyl amino purine

Table 4: Tukey's Studentized Range (HSD) Test for weight of B. monnieri plantlets grown on micropropagated on humin media (vermicompost treated with acid-alkali) with and without chemical supplements

\begin{tabular}{cccccc}
\hline Source & DF & Anova SS & Mean Square & F Value & Pr $>$ F \\
\hline Types of Media & 3 & 16743.20 & 5581.067 & 19.24 & $<.0001$ \\
\hline & Mean & N & Tukey Grouping & \\
\hline Humin only & 139.60 & 5 & & A & \\
Humin+micronutrients & 125.60 & 5 & $\mathrm{~A}$ & \\
Humin+vitamins & 124.00 & 5 & $\mathrm{~A}$ & \\
Humin+IAA+BAP & 64.40 & 5 & $\mathrm{~B}$ & \\
\hline
\end{tabular}

Note: $\mathrm{IAA}=$ Indole-3-acetic acid; $\mathrm{BAP}=6$-Benzyl amino purine

Table 5: Tukey's Studentized Range (HSD) Test for percentage survival of B. monnieri plantlets grown on Humin media (vermicompost treated with acid-alkali) with and without chemical supplements

\begin{tabular}{lccccc}
\hline \multicolumn{1}{c}{ Source } & DF & Anova SS & Mean Square & F Value & Pr $>$ F \\
\hline Types of Media & 3 & 2440.00 & 813.33 & Infty & $<.0001$ \\
\hline Humin only & Mean & N & Tukey Grouping & & \\
Humin+Vitamins & 100.0 & 5 & A & \\
Humin+Micronutrients & 92.0 & 5 & B & \\
Humin+IAA+BAP & 90.0 & 5 & $\mathrm{C}$ & \\
\hline
\end{tabular}

Note: $\mathrm{IAA}=$ Indole-3-acetic acid; $\mathrm{BAP}=6$-Benzyl amino purine 
Table 6: Student's t test to compare the means of weight of plantlets grown on Humin medium with and without chemical supplements and vermicompost extract medium with and without chemical supplements

\begin{tabular}{ccccc}
\cline { 2 - 5 } Media & $\overline{\mathbf{X}} \pm \mathbf{S E}$ & Media & $\overline{\mathbf{X}}_{ \pm \mathbf{S E}}$ & t statistical value \\
\hline VC extract only & $414.0 \pm 35.78$ & Humin only & $139.6 \pm 2.06$ & $0.00009^{* *}$ \\
VC extract+ IAA+BAP & $362.8 \pm 29.32$ & Humin+IAA+BAP & $64.4 \pm 6.94$ & $0.0000001^{* *}$ \\
VC extract + vitamins & $360.8 \pm 27.95$ & Humin+vitamins & $124.0 \pm 13.06$ & $0.00009^{* *}$ \\
VCextract+Micronutrients & $133.8 \pm 7.89$ & Humin+micro nutrients & $125.6 \pm 12.79$ & 0.501 \\
\hline VC $=$ Vermicompost & & & &
\end{tabular}

Note: $\quad \mathrm{P} \leq 0.05: *$ Significance at 5 per cent level $* *$ Significance at 1 per cent level

\section{Results}

Humin left behind after acid and alkali treatment were given several washings with sterile distilled water and it was used as the medium for growing explants of B.monnieri. The number of roots developed from the explant could not be measured as the media was dark and the visibility of roots was obscure. Table 1 and 2 indicated the differentiation of shoots and nodes in the residue of vermicompost (humin) with or without other additives but were not significantly different. This shows that there is presence of growth promoter biomolecules even in the residue after acid- alkali extraction. Tukey's Studentized Range (HSD) Test has clearly indicated that development of nodes was higher in humin alone without any other supplements (Table 2). The $\mathrm{F}$ value was 5.07 and $\operatorname{Pr}>\mathrm{F}$ was 0.0118 . Other treatments with humin did not significantly support the development of nodes (Table 2). Tukey's Studentized Range (HSD) Test has clearly indicated that development of leaves from nodes was significantly higher in humin alone without any other supplements (Table 3). The F value was 5.5 and $\operatorname{Pr}>$ F was 0.0087. Other treatments with humin did not significantly support the growth of leaves (Table 3). The $\mathrm{F}$ value was 5.5 and $\mathrm{Pr}>\mathrm{F}$ was 0.0087. The weight of the plantlets (in milligrams) was significantly higher in the humin medium and humin supplemented with vitamins and micronutrients but was least in the humin medium with growth regulators (Table 4). The difference observed was at the level of $<0.0001$. The explant development on humin alone has shown the significant percentage survival of in vitro micropropagated plantlets when compared with other treatments (Table 5). Explants responded maximum to humin only but not so on adding the supplements and the level of significance was at $\mathrm{Pr}$ $>$ F was $<0.0001$.

Student's t-test for Humin and Vermicompost extract (weight of plantlets in milligrams)

Student's t-test for humin and vermicompost extract (weight of plantlets in milligrams) is shown in Table 6. Aqueous extract of vermicompost has shown that though there was growth induction in humin fraction of vermicompost, the maximum growth stimulatory effect was found in aqueous extract of vermicompost which can be made out from the Student's t-test performed to compare the means of weight of plantlets grown on humin and vermicompost extract media with and without chemical supplements respectively. The probability of this result, assuming the null hypothesis is 0.0014 .

\section{Discussion}

Present study on micropropagation of B. monnieri was based on research studies reported by Mathur and Kumar (1998); Tiwari et al., 1998; 2000); Banerjee and Shrivastava (2008). Earlier reports available on $B$. monnieri demonstrated that successful plant regeneration is through axillary nodes, internodes and young leaves on media with very high concentrations of cytokinin (Shrivastava and Rajani, 1999). The effect of different concentrations of cytokinin (BAP) and auxin (IAA) on shoot induction of $B$. monnieri for rapid and large-scale multiplication at a cost-effective level was studied. Alternatively, in the present study using humin of vermicompost as plant tissue culture media supported the growth and development of roots, shoots, nodes, leaves, good weight gain of plantlets and good survival of plantlets. Explants remained green and fresh but failed to grow any further in growth-regulator-free MS medium. To initiate the study, nodal, leaf and shoot tip explants were taken from field established plants.

Leaf explants of Nicotiana plumbaginifolia were compared in cultures supplemented with hormones or humic substances (extracted from faeces of Allolobophora caliginosa) of various molecular complexity and concentration. It was shown that the humic substances (F1, F2, and $\mathrm{T}$ ) at the concentration of $1 \mathrm{mg} / \mathrm{L}$ produced greater leaf explants than those grown in the control. Furthermore, humic fractions like gibberellic acid alone induced a rhizogenic activity in leaf explants. Nicotiana sp. tissue treated with humic fractions revealed the esterase enzyme pattern, which was attributable to indoleacetic acid (Muscolo et al., 1993).

The present study has shown that there is presence of growth promoter bio molecules in the residue even after acid- alkali extraction of vermicompost. The explant development of B. monnieri on humin alone has shown the significant development of leaves, weight of plantlets and percentage survival of in vitro micropropagated plantlets. Aqueous extract of vermicompost has shown that though there was growth induction in humin fraction of vermicompost, the maximum growth stimulatory 
effect was found in aqueous extract of vermicompost

\section{Conclusion}

The growth responses were most probably due to the hormone-like activity of humic acids from the vermicompost. This study shows that there is presence of growth promoter biomolecules even in the residue after acid - alkali extraction. Cost analysis carried out during this study confirms that vermicompost is more economical (Rs. 10.227/per litre) compared to conventional MS medium (Rs. 66.576/- per litre) used in plant tissue culture (Kashyap et al., 2015). It can reach farmers as affordable plantlets, to develop in agricultural fields for mass production. The study has indicated that by standardizing the technique, it is possible to develop the plants through micropropagation in an economical way.

\section{Acknowledgements}

The authors thank Prof. Rajanna (Botanical garden, Gandhi Krishi Vigyan Kendra, Bengalure) for supplying the plant samples to conduct research work. Authors also would like to thank Mount Carmel College, Bengaluru for providing lab and other chemical supplements for successful completion of the research work.

\section{References}

1. Cacco G, Dell'Agnola G. Plant growth regulator activity of soluble humic complex. Can J Soil Sci. 1984, 64, 225228.

2. Nardi S, Panuccio MR, Abenavoli MR, Muscolo A. Auxin-like effect of humic substances extracted from faeces of Allolobophora caliginosa and A. rosea. Soil Biol Biochem. 1994, 26, 1341-1346.

3. Masciandaro G, Ceccanti B, Garcia C. Soil agroecological management: fert-irrigation and vermicompost treatments. Biores Technol. 1997, 59, 199-206.

4. Schnitzer M. Soil organic matter: the next 75 years. Soil Sci. 1991, 151, 41-58.

5. Vaughan D, Malcolm RE. Influence of humic substances on growth and physiological process. In: Vaughan D, Malcolm RE., editors. Soil Organic Matter and Biological Activity. Dordrecht, the Netherlands: Kluwer Academic Publishers. 1985, pp. 37-75.

6. Chen Y, Aviad T. Effects of humic substances on plant growth. (In: MacCarthy P, Clapp CE, Malcolm RL, Bloom PR., Eds). Humic Substances in Soil and Crop Science: Selected Readings. Madison, WI: American Society of Agronomy Inc., Soil Science of America, Inc. 1990, 161-186.

7. Atiyeh RM, Lee S, Edwards CA, Arancon NQ, Metzger JD. The influence of humic acids derived from earthworm-processed organic wastes on plant growth. Bioresource Technology. 2002, 84, 7-14.

8. Canellas L, Olivares F, Okorokova-Façanha A, Façanha A. Humic Acids Isolated from Earthworm Compost Enhance Root Elongation, Lateral Root Emergence, and
Plasma Membrane H+-ATPase Activity in Maize Roots. Plant Physiol. 2002, 130, 1951-1957.

9. Muscolo A, Felici M, Concheri G, Nardi S. Effect of earthworm humic substances on esterase and peroxidase activity during growth of leaf explants of Nicotiana plumbaginifoli. Biomedical and Life Sciences. 1993, 15, 127131.

10. Atiyeh RM, Edwards CA, Subler S, Metzger JD. Pig manure vermicompost as a component of a horticultural bedding plant medium: effects on physicochemical properties and plant growth. Bioresour Technol. 2001, 78, 11-20.

11. Rastogi S, Pal R, Kulshreshtha DK. 1994. Bacoside A3-a triterpenoidsaponins from Bacopa monnieri. Phytochemistry, 1994, 36, 133-137.

12. National Medicinal Plants Board (NMPB) and Technology Information Forecasting and Assessment Council (TIFAC), Department of Science and Technology, Government of India. 2007.

13. Tiwari V, Singh BD, Tewari KN. Shoot regeneration and somatic embryogenesis from different explants of Brahmi (Bacopa monniera (L.) Wettst). Plant Cell Rep. 1998, 17, 538-543.

14. Tiwari V, Tewari KN, Singh BD. Suitability of liquid cultures or in vitro multiplication of Bacopa monnira (L.) Wettst. Phytomorphology. 2000, 50, 337-342.

15. Tiwari V, Tewari KN, Singh BD. Comparative studies of cytokinins on in vitro propagation of Bacopa monniera. Plant Cell Tissue Organ Cult. 2001, 66, 9-16.

16. Tiwari V, Tewari KN, Singh BD. Shoot bud regeneration from different explants of Bacopa monniera (L.) Wettst.by trimethoprim and bavistin. Plant Cell Rep. 2006, 25, 629635.

17. Shrivastava N, Rajani M. Multiple shoot regeneration and tissue culture studies on Bacopa monnieri (L.) Pennell. Plant Cell Rep. 1999, 18, 919-923.

18. Tejavathi DH, Shailaja KS. Regeneration of plants from the cultures of Bacopa monnieri (L.) Pennell. Phytomorphology. 1999, 49, 447-452.

19. Mohapatra HP, Rath SP. In vitro studies of Bacopa monnieri-an important medicinal plant with reference to its biochemical variations. Indian J Exp Biol. 2005, 43, 373-376.

20. Ramesh M, Saravanakumar RM, Pandian KS. Benzyl amino purine and adenine sulphate induced multiple shoot and root induction from nodal explants of Brahmi, Bacopa monnieri (Linn.) Penn. Nat Prod Radiance. 2006, 5, 44-51.

21. Praveen N, Naik PM, Manohar SH, Nayeem A, Murthy HN. In vitro regeneration of brahmi shoots using semisolid and liquid cultures and quantitative analysis of bacoside A. Acta Physiol plant. 2009, 31, 723-728.

22. Ceasar AS, Maxwell LS, Prasad BK, Karthigan M, Ignacimuthu S. Highly efficient shoot regeneration of Bacopa monnieri (L.) using a two-stage culture procedure and assessment of genetic integrity of micropropagated plants by RAPD. Acta Physiologiae Plantarum. 2009, 32, 443-452. 
23. Murashige T, Skoog F. A revised medium for rapid growth and bioassay with tobacco tissue cultures. Physiology and plants. 1962, 15, 472-497.

24. Mathur S, Kumar S. Phytohormone self-sufficiency for regeneration in the leaf and stem explants of Bacopa monnieri. Journal of Medicinal and Aromatic Plant Sciences. 1998, 20, 1056-1059.

25. Tiwari V, Singh BD, Tewari KN. Shoot regeneration and somatic embryogenesis from different explants of Brahmi (Bacopa monniera (L.) Wettst). Plant Cell Rep. 1998, 17, 538-543.

26. Tiwari V, Tewari KN, Singh BD. Suitability of liquid cultures or in vitro multiplication of Bacopa monnira (L.) Wettst. Phytomorphology. 2000, 50, 337-342.

27. Banerjee M, Shrivastava S. An improved protocol for in vitro multiplication of Bacopa monnieri (L.). World J Microbiol Biotechnol. 2008, 8, 1355-1359.
28. Shrivastava N, Rajani M. Multiple shoot regeneration and tissue culture studies on Bacopa monnieri (L.) Pennell. Plant Cell Rep. 1999, 18, 919-923.

29. Muscolo A, Felici M, Concheri G, Nardi S. Effect of earthworm humic substances on esterase and peroxidase activity during growth of leaf explants of Nicotiana plumbaginifoli. Biomedical and Life Sciences. 1993, 15, 127131.

30. Kashyap S, Kapoor N, Kale RD. Callus Induction and Tissue Differentiation of Tinospora cordifolia on Using Vermicompost and its Extracts along with Coelomic Fluid as Tissue Culture Media Horizon Journal of Micro. Biotech. Res. 2015 1(1): 001-007.

\section{Cite this article as:}

Suman Kashyap Neera Kapoor and Radha D. Kale. Micropropagation of B. monnieri using humin media in plant tissue culture. Annals of Plant Sciences 6.5 (2017) $p p$. 1625-1629.

DOI: http://dx.doi.org/10.21746/aps.2017.05.004

Source of support: Nil.

Conflict of interest: Nil 